Appl. Set-Valued Anal. Optim. 1 (2019), No. 2, pp. 105-112

Available online at http://asvao.biemdas.com

https://doi.org/10.23952/asvao.1.2019.2.02

\title{
A STRONG CONVERGENCE THEOREM FOR THE SPLIT COMMON FIXED-POINT PROBLEM OF DEMICONTRACTIVE MAPPINGS
}

\author{
JIAYAN WANG, XIAOLI FANG*
}

Department of Mathematics, Shaoxing University, Shaoxing 312000, China

\begin{abstract}
In this paper, we introduce an iterative algorithm to study the split common fixed-point problem of demicontractive mappings in Hilbert spaces. Strong convergence of the proposed algorithm is obtained in Hilbert spaces.

Keywords. Split common fixed-point problem; Demicontractive mapping; Strong convergence; Iterative algorithm.
\end{abstract}

2010 Mathematics Subject Classification. 47H09, 47J25.

\section{INTRODUCTION}

Let $H_{1}$ and $H_{2}$ be two real Hilbert spaces equipped up their own inner product $\langle\cdot, \cdot\rangle$ and norm $\|\cdot\|$. Let $S: H_{1} \rightarrow H_{1}$ and $T: H_{2} \rightarrow H_{2}$ be two nonlinear mappings. $F(S)$ and $F(T)$ stand for the fixed point sets of $S$ and $T$, respectively. Let $A: H_{1} \rightarrow H_{2}$ be a bounded linear operator with its adjoint $A^{*}$.

The split common fixed-point problem (SCFPP) is to find a point $x^{*} \in H_{1}$ such that

$$
x^{*} \in F(S) \text { and } A x^{*} \in F(T) .
$$

Specially, if $S$ and $T$ are both orthogonal projections, then SCFPP (1.1) is reduced to the well-known split feasibility problem (SFP) [1], which consists of finding a point $x^{*}$ such that

$$
x^{*} \in C \text { and } A x^{*} \in Q,
$$

where $C \subseteq H_{1}$ and $Q \subseteq H_{2}$ are the nonempty closed convex sets and $A$ is a bounded linear operator. These two problems recently have been extensively investigated since they play an import role in various areas including signal processing and image reconstruction (see, e.g., $[3,6,8,9,13,14,16,17]$ for further details).

To solve the SCFPP (1.1), Censor and Segal [2] proposed the following iterative method: for any initial guess $x_{1} \in H_{1}$, define $\left\{x_{n}\right\}$ recursively by

$$
x_{n+1}=S\left(x_{n}-\lambda A^{*}(I-T) A x_{n}\right),
$$

where $S$ and $T$ are directed operators. The further generalization of this algorithm was studied by Moudafi [5] for demicontractive operators. Under suitable conditions, he proved that the sequence $\left\{x_{n}\right\}$ converges weakly to a point of the SCFPP (1.1).

\footnotetext{
*Corresponding author.

E-mail address: fx10418@126.com (X. Fang).

Received February 9, 2019; Accepted May 12, 2019.
}

(C)2019 Applied Set-Valued Analysis and Optimization 
Recently, Wang [11] introduced the following new iterative algorithm for the SCFPP (1.1) of firmly nonexpansive mappings:

Algorithm 1.1. [11] Choose an arbitrary initial guess $x_{0}$.

Step 1. Given $x_{n}$, compute the next iteration via the formula:

$$
x_{n+1}=x_{n}-\rho_{n}\left[x_{n}-S x_{n}+A^{*}(I-T) A x_{n}\right], n \geq 0 .
$$

Step 2. If the following equality

$$
\left\|x_{n+1}-S x_{n+1}+A^{*}(I-T) A x_{n+1}\right\|=0
$$

holds, then stop; otherwise go to Step 1.

Under suitable conditions, Wang obtained a weak convergence result.

Very recently, Yao et al. [18] extended Wang's [11] result from firmly nonexpansive mappings to more general demiconstractive mappings. Also they established a weak convergence theorem. Inspired by the above work, we put forward a question: Can we give a modification of Algorithm 1.1 and get a strong convergence result for the SCFPP (1.1) of demicontractive mappings? The main aim of this paper is to give a positive answer to the above question.

\section{PRELIMINARIES}

Throughout this paper, let $R$ be the set of real numbers and let $H$ be a real Hilbert space with inner product $\langle\cdot, \cdot\rangle$, and norm $\|\cdot\|$. Let $\left\{x_{n}\right\}$ be a sequence in $H$. We denote the strong convergence of $\left\{x_{n}\right\}$ to $x \in H$ by $x_{n} \rightarrow x$ and the weak convergence by $x_{n} \rightarrow x$. Let $T$ be a mapping of $C$ into $H$. We denote by $F(T)$ the set of fixed points of $T$.

In order to facilitate our investigation in this paper, we recall some definitions as follows.

Definition 2.1. A mapping $T: H \rightarrow H$ is said to be

(i) nonexpansive if

$$
\|T x-T y\| \leq\|x-y\|, \quad \forall x, y \in H ;
$$

(ii) quasi-nonexpansive if $F(T) \neq \emptyset$ and

$$
\|T x-q\| \leq\|x-q\|, \quad \forall(x, q) \in H \times F(T) ;
$$

(iii) firmly nonexpansive if

$$
\|T x-T y\|^{2} \leq\|x-y\|^{2}-\|(I-T) x-(I-T) y\|^{2}, \forall x, y \in H ;
$$

(iv) directed if

$$
\|T x-q\|^{2} \leq\|x-q\|^{2}-\|x-T x\|^{2}, \quad \forall(x, q) \in H \times F(T) ;
$$

(v) $\mu$-demicontractive if there exists a constant $\mu \in(-\infty, 1)$ such that

$$
\|T x-q\|^{2} \leq\|x-q\|^{2}+\mu\|x-T x\|^{2}, \forall(x, q) \in H \times F(T),
$$

which is equivalent to

$$
\langle x-T x, x-q\rangle \geq \frac{1-\mu}{2}\|x-T x\|^{2} .
$$


Remark 2.1. Notice that 0 -demicontractive is exactly quasi-nonexpansive. In particular, we say that it is quasi-strict pseudo-contractive [6] if $0 \leq \mu<1$. Moreover, if $\mu \leq 0$, every $\mu$-demicontractive mapping becomes a quasi-nonexpansive mapping. Therefore, it is sufficient to only take $\mu \in(0,1)$ in (v) of Definition 2.1, or as the notion of quasi-strict pseudo-contraction due to [6].

Recall that the metric (or nearest point) projection from $H$ onto $C$ is the mapping $P: H \rightarrow C$ which assigns to each point $x \in H$ the unique point $P_{C} x \in C$ satisfying the property $\left\|x-P_{C} x\right\|=\inf _{y \in C}\|x-y\|$. It is well known [10] that $P_{C} x$ is characterized by the inequality

$$
\left\langle x-P_{C} x, y-P_{C} x\right\rangle \leq 0, \forall y \in C .
$$

Let us also recall that $I-T$ is said to be demiclosed at zero, if for any sequence $\left\{x_{n}\right\} \subset H$ and $x^{*} \in H$, we have

$$
\left.\begin{array}{l}
x_{n} \rightarrow x^{*} \\
(I-T) x_{n} \rightarrow 0
\end{array}\right\} \Rightarrow x^{*}=T x^{*}
$$

As a special case of the demicloseness principle on uniformly convex Banach spaces given by [4], we know that if $C$ is a nonempty closed convex subset of a Hilbert space $H$, and $T: C \rightarrow H$ is a nonexpansive mapping. Then the mapping $I-T$ is demiclosed on $C$. Now the following question is naturally raised:

If $T: C \rightarrow H$ is quasi-nonexpansive, is $I-T$ still demiclosed on $C$ ?

The answer is negative even at 0 as follows.

Example 2.1. [12, Example 2.11] The mapping $T:[0,1] \rightarrow[0,1]$ is defined by

$$
T x=\left\{\begin{array}{l}
\frac{x}{5}, x \in\left[0, \frac{1}{2}\right], \\
x \sin \pi x, x \in\left(\frac{1}{2}, 1\right] .
\end{array}\right.
$$

Then $T$ is a quasi-nonexpansive mapping, but $I-T$ is not demiclosed at 0 .

In fact, $F(T)=\{0\}$. For any $x \in\left[0, \frac{1}{2}\right]$, we have

$$
|T x-0|=\left|\frac{x}{5}-0\right| \leq|x-0|,
$$

and for any $x \in\left(\frac{1}{2}, 1\right]$, we have

$$
|T x-0|=|x \sin \pi x-0| \leq|x-0| .
$$

Thus $T$ is quasi-nonexpansive. Taking $\left\{x_{n}\right\} \subset\left(\frac{1}{2}, 1\right]$ and $x_{n} \rightarrow \frac{1}{2}(n \rightarrow \infty)$, we have

$$
\left|(I-T) x_{n}\right|=\left|x_{n}\left[1-\sin \pi x_{n}\right]\right| \rightarrow 0(n \rightarrow \infty) .
$$

But $T \frac{1}{2}=\frac{1}{10} \neq \frac{1}{2}$, i.e., $(I-T) \frac{1}{2} \neq 0$, so $I-T$ is not demiclosed at 0 .

In what follows, we give some lemmas which are needed for our main convergence theorem.

Lemma 2.1. [15] Assume that $\left\{a_{n}\right\}$ is a sequence of non-negative real numbers such that

$$
a_{n+1} \leq\left(1-\gamma_{n}\right) a_{n}+\gamma_{n} \delta_{n}+\varepsilon_{n}, n \geq 0,
$$

where $\left\{\gamma_{n}\right\}$ is a sequence in $(0,1)$ and $\left\{\delta_{n}\right\}$ is a sequence in $R$ such that

(i) $\sum_{n=0}^{\infty} \gamma_{n}=\infty$;

(ii) $\sum_{n=0}^{\infty} \varepsilon_{n}<\infty$;

(iii) $\limsup _{n \rightarrow \infty} \delta_{n} \leq 0$ or $\sum_{n=1}^{\infty} \gamma_{n}\left|\delta_{n}\right|<\infty$.

Then $\lim _{n \rightarrow \infty} a_{n}=0$. 
Lemma 2.2. [6] Assume $C$ is a closed convex subset of a Hilbert space H. Let $T: C \rightarrow C$ be a selfmapping of $C$. If $T$ is a $\mu$-demicontractive mapping (which is also called $\mu$-quasi-strictly-contraction in [6]), then the fixed point set $F(T)$ is closed and convex.

Lemma 2.3. [7] [The demiclosedness principle of nonexpansive mappings] If $V: H \rightarrow H$ is a nonexpansive mapping, then $I-V$ is demiclosed at zero.

\section{MAIN RESULTS}

In this section, we always assume that $H_{1}, H_{2}$ are real Hilbert spaces. Let $S: H_{1} \rightarrow H_{1}$ and $T: H_{2} \rightarrow H_{2}$ be two demicontractive mappings with constants $\beta \in(0,1)$ and $\mu \in(0,1)$, respectively. Let $A: H_{1} \rightarrow H_{2}$ be a bounded linear operators with its adjoints $A^{*}$.

We use $\Omega$ to denote the solution set of problem (1.1), that is,

$$
\Omega=\{z: z \in F(S) \text { and } A z \in F(T)\}=F(S) \cap A^{-1}(F(T)) .
$$

Throughout, assume $\Omega \neq \emptyset$.

Algorithm 3.1. Step 1. Choose an anchor $u \in H_{1}$ and initial guess $x_{0} \in H_{1}$ arbitrarily.

Step 2. If

$$
\left\|x_{n}-S x_{n}+A^{*}(I-T) A x_{n}\right\|=0,
$$

then stop, and $x_{n}$ is a solution of problem (1.1); otherwise, go on to the next step.

Step 3. Update $x_{n+1}$ via the iteration formula:

$$
x_{n+1}=\alpha_{n} u+\left(1-\alpha_{n}\right)\left[x_{n}-\rho_{n}\left(x_{n}-S x_{n}+A^{*}(I-T) A x_{n}\right)\right],
$$

and return to Step 2.

The following lemma can be found in [18].

Lemma 3.1. $z^{\dagger}$ solves (1.1) iff $\left\|z^{\dagger}-S z^{\dagger}+A^{*}(I-T) A z^{\dagger}\right\|=0$.

Proof. If $z^{\dagger}$ solves (1.1), then $z^{\dagger}=S z^{\dagger}$ and $(I-T) A z^{\dagger}=0$. It is obvious that

$$
\left\|z^{\dagger}-S z^{\dagger}+A^{*}(I-T) A z^{\dagger}\right\|=0 .
$$

To see the converse, we assume that $\left\|z^{\dagger}-S z^{\dagger}+A^{*}(I-T) A z^{\dagger}\right\|=0$. For any $z \in \Omega$, we obtain

$$
\begin{aligned}
0 & =\left\|z^{\dagger}-S z^{\dagger}+A^{*}(I-T) A z^{\dagger}\right\|\left\|z^{\dagger}-z\right\| \\
& \geq\left\langle z^{\dagger}-S z^{\dagger}+A^{*}(I-T) A z^{\dagger}, z^{\dagger}-z\right\rangle \\
& =\left\langle z^{\dagger}-S z^{\dagger}, z^{\dagger}-z\right\rangle+\left\langle A^{*}(I-T) A z^{\dagger}, z^{\dagger}-z\right\rangle \\
& =\left\langle z^{\dagger}-S z^{\dagger}, z^{\dagger}-z\right\rangle+\left\langle(I-T) A z^{\dagger}, A z^{\dagger}-A z\right\rangle .
\end{aligned}
$$

Since $S$ and $T$ are demicontractive, we deduce from (2.2) that

$$
\left\langle z^{\dagger}-S z^{\dagger}, z^{\dagger}-z\right\rangle \geq \frac{1-\beta}{2}\left\|z^{\dagger}-S z^{\dagger}\right\|^{2}
$$

and

$$
\left\langle(I-T) A z^{\dagger}, A z^{\dagger}-A z\right\rangle \geq \frac{1-\mu}{2}\left\|(I-T) A z^{\dagger}\right\|^{2} .
$$


By (3.1)-(3.3), we get

$$
\begin{aligned}
0 & \geq\left\langle z^{\dagger}-S z^{\dagger}, z^{\dagger}-z\right\rangle+\left\langle(I-T) A z^{\dagger}, A z^{\dagger}-A z\right\rangle \\
& \geq \frac{1-\beta}{2}\left\|z^{\dagger}-S z^{\dagger}\right\|^{2}+\frac{1-\mu}{2}\left\|(I-T) A z^{\dagger}\right\|^{2}
\end{aligned}
$$

Since $\beta, \mu \in(0,1)$, we deduce $z^{\dagger} \in F(S)$ and $A z^{\dagger} \in F(T)$ by (3.4). Therefore, $z^{\dagger}$ solves the problem (1.1). The proof is completed.

Based Lemma 3.1, we may assume that Algorithm 3.1 generates an infinite sequence $\left\{x_{n}\right\}$, in general since, otherwise, the algorithm terminates in a finite number of iterations and a solution is found.

Lemma 3.2. Suppose that $\left\{x_{n}\right\}$ is a bounded sequence such that

$$
\lim _{n \rightarrow \infty}\left\|x_{n}-S x_{n}+A^{*}(I-T) x_{n}\right\|=0
$$

Then $\lim _{n \rightarrow \infty}\left\|x_{n}-S x_{n}\right\|=0$ and $\lim _{n \rightarrow \infty}\left\|(I-T) A x_{n}\right\|=0$.

Proof. Set $y_{n}=x_{n}-S x_{n}+A^{*}(I-T) A x_{n}, z_{n}=x_{n}-\rho_{n} y_{n}$. For any $z \in \Omega$, we get

$$
\left\langle y_{n}, x_{n}-z\right\rangle=\left\langle x_{n}-S x_{n}, x_{n}-z\right\rangle+\left\langle(I-T) A x_{n}, A x_{n}-A z\right\rangle .
$$

Since $z \in F(S)$ and $A z \in F(T),\left\|y_{n}\right\| \rightarrow 0$ and $\left\{x_{n}\right\}$ is bounded, we have from (2.1) that

$$
\frac{1-\beta}{2}\left\|x_{n}-S x_{n}\right\|^{2}+\frac{1-\mu}{2}\left\|(I-T) A x_{n}\right\|^{2} \leq\left\langle y_{n}, x_{n}-z\right\rangle \leq\left\|y_{n}\right\|\left\|x_{n}-z\right\| \rightarrow 0
$$

Therefore, we obtain from $\beta, \mu \in(0,1)$ that $\lim _{n \rightarrow \infty}\left\|x_{n}-S x_{n}\right\|=0$ and $\lim _{n \rightarrow \infty}\left\|(I-T) A x_{n}\right\|=0$. The proof is completed.

Theorem 3.1. Let the sequences $\left\{\alpha_{n}\right\} \subseteq(0,1)$ and $\left\{\rho_{n}\right\} \subseteq(0,2 \tau)$, where $\tau=\frac{\min \{1-\beta, 1-\mu\}}{4 \max \left\{1,\|A\|^{2}\right\}}$. Assume the following conditions are satisfied:

(a) $I-S$ and $I-T$ are demiclosed at zero;

(b) $\sum_{n=0}^{\infty} \rho_{n}^{2}<\infty$;

(c) $\lim _{n \rightarrow \infty} \alpha_{n}=0$ and $\sum_{n=0}^{\infty} \alpha_{n}=\infty$;

(d) $\lim _{n \rightarrow \infty} \frac{\alpha_{n}}{\rho_{n}}=0$.

Then the sequence $\left\{x_{n}\right\}$ generated by Algorithm 3.1 converges strongly to a solution $z$ of the problem (1.1), where $z=P_{\Omega} u$.

Proof. By Lemma 2.2, we have that $F(S)$ and $F(T)$ are both closed convex. Since $A$ is bounded linear, $A^{-1}(F(T))$ is closed convex. Hence $\Omega$ is closed convex. Put $z=P_{\Omega} u$ and set $y_{n}=x_{n}-S x_{n}+A^{*}(I-T) A x_{n}$ and $z_{n}=x_{n}-\rho_{n} y_{n}$. 
First, we show that $\left\{x_{n}\right\}$ is bounded. Indeed, by (2.1), we have

$$
\begin{aligned}
\left\langle y_{n}, x_{n}-z\right\rangle & =\left\langle x_{n}-S x_{n}+A^{*}(I-T) A x_{n}, x_{n}-z\right\rangle \\
& =\left\langle x_{n}-S x_{n}, x_{n}-z\right\rangle+\left\langle(I-T) A x_{n}, A x_{n}-A z\right\rangle \\
& \geq \frac{1-\beta}{2}\left\|x_{n}-S x_{n}\right\|^{2}+\frac{1-\mu}{2}\left\|(I-T) A x_{n}\right\|^{2} \\
& \geq \frac{1-\beta}{2}\left\|x_{n}-S x_{n}\right\|^{2}+\frac{1-\mu}{2\|A\|^{2}}\left\|A^{*}(I-T) A x_{n}\right\|^{2} \\
& \geq \frac{\min \{1-\beta, 1-\mu\}}{2 \max \left\{1,\|A\|^{2}\right\}}\left(\left\|x_{n}-S x_{n}\right\|^{2}+\left\|A^{*}(I-T) A x_{n}\right\|^{2}\right) \\
& \geq \frac{\min \{1-\beta, 1-\mu\}}{4 \max \left\{1,\|A\|^{2}\right\}}\left(\left\|x_{n}-S x_{n}+A^{*}(I-T) A x_{n}\right\|\right)^{2}, \\
& =\tau\left\|y_{n}\right\|^{2},
\end{aligned}
$$

where

$$
\tau=\frac{\min \{1-\beta, 1-\mu\}}{4 \max \left\{1,\|A\|^{2}\right\}} .
$$

It follows from (3.5) and $\rho_{n} \in(0,2 \tau)$ that

$$
\begin{aligned}
\left\|z_{n}-z\right\|^{2} & =\left\|x_{n}-z-\rho_{n} y_{n}\right\|^{2} \\
& =\left\|x_{n}-z\right\|^{2}-2 \rho_{n}\left\langle y_{n}, x_{n}-z\right\rangle+\rho_{n}^{2}\left\|y_{n}\right\|^{2} \\
& \leq\left\|x_{n}-z\right\|^{2}-2 \rho_{n} \tau\left\|y_{n}\right\|^{2}+\rho_{n}^{2}\left\|y_{n}\right\|^{2} \\
& =\left\|x_{n}-z\right\|^{2}-\rho_{n}\left(2 \tau-\rho_{n}\right)\left\|y_{n}\right\|^{2} \\
& \leq\left\|x_{n}-z\right\|^{2} .
\end{aligned}
$$

From Algorithm 3.1 and (3.7), we obtain

$$
\begin{aligned}
\left\|x_{n+1}-z\right\|^{2} & =\left\|\alpha_{n}(u-z)+\left(1-\alpha_{n}\right)\left(z_{n}-z\right)\right\|^{2} \\
& \leq \alpha_{n}\|u-z\|^{2}+\left(1-\alpha_{n}\right)\left\|z_{n}-z\right\|^{2} \\
& \leq \alpha_{n}\|u-z\|^{2}+\left(1-\alpha_{n}\right)\left\|x_{n}-z\right\|^{2} .
\end{aligned}
$$

By mathematical induction, we get

$$
\left\|x_{n}-z\right\|^{2} \leq \max \left\{\|u-z\|^{2},\left\|x_{0}-z\right\|^{2}\right\}
$$

for all $n \geq 0$. Hence $\left\{x_{n}\right\}$ is bounded. From (3.5) and (3.7), $\left\{y_{n}\right\}$ and $\left\{z_{n}\right\}$ are also bounded. By Algorithm 3.1 and (3.6), we have

$$
\begin{aligned}
\left\|x_{n+1}-z\right\|^{2}= & \left\|\left(1-\alpha_{n}\right)\left(z_{n}-z\right)+\alpha_{n}(u-z)\right\|^{2} \\
\leq & \left(1-\alpha_{n}\right)\left\|z_{n}-z\right\|^{2}+2 \alpha_{n}\left\langle u-z, x_{n+1}-z\right\rangle \\
\leq & \left(1-\alpha_{n}\right)\left\|x_{n}-z\right\|^{2}-2 \rho_{n} \tau\left(1-\alpha_{n}\right)\left\|y_{n}\right\|^{2}+\rho_{n}^{2}\left\|y_{n}\right\|^{2} \\
& +2 \alpha_{n}\left\langle u-z, x_{n+1}-z\right\rangle \\
\leq & \left(1-\alpha_{n}\right)\left\|x_{n}-z\right\|^{2}+\alpha_{n} b_{n}+\rho_{n}^{2} M,
\end{aligned}
$$


where $M=\sup _{n \geq 0}\left\{\left\|y_{n}\right\|^{2}\right\}$ and

$$
b_{n}=2\left\langle u-z, x_{n+1}-z\right\rangle-2 \tau\left(1-\alpha_{n}\right) \frac{\rho_{n}}{\alpha_{n}}\left\|y_{n}\right\|^{2} .
$$

Next, we claim that $\lim \sup _{n \rightarrow \infty} b_{n} \leq 0$. Since $\left\{b_{n}\right\}$ is bounded from above, $\lim _{\sup _{n \rightarrow \infty}} b_{n}$ is finite. The condition $(b)$ implies that $\rho_{n} \rightarrow 0$. Then

$$
\left\|x_{n+1}-x_{n}\right\|=\left\|\alpha_{n}\left(u-x_{n}\right)-\left(1-\alpha_{n}\right) \rho_{n} y_{n}\right\| \leq \alpha_{n}\left\|u-x_{n}\right\|+\rho_{n}\left\|y_{n}\right\| \rightarrow 0
$$

due to $\rho_{n} \rightarrow 0$ and $\alpha_{n} \rightarrow 0$. Taking a subsequence $\left\{x_{n_{k}}\right\} \subseteq\left\{x_{n}\right\}$ such that

$$
\begin{aligned}
\limsup _{n \rightarrow \infty} b_{n} & =\lim _{k \rightarrow \infty}\left[2\left\langle u-z, x_{n_{k}+1}-z\right\rangle-2 \tau\left(1-\alpha_{n_{k}}\right) \frac{\rho_{n_{k}}}{\alpha_{n_{k}}}\left\|y_{n_{k}}\right\|^{2}\right] \\
& =\lim _{k \rightarrow \infty}\left[2\left\langle u-z, x_{n_{k}}-z\right\rangle-2 \tau\left(1-\alpha_{n_{k}}\right) \frac{\rho_{n_{k}}}{\alpha_{n_{k}}}\left\|y_{n_{k}}\right\|^{2}\right] .
\end{aligned}
$$

Since $\left\{x_{n}\right\}$ is bounded, we may, with no loss of generality, assume that $\left\{x_{n_{k}}\right\}$ is weakly convergent to some point $x^{*}$. Thus

$$
\lim _{k \rightarrow \infty}\left\langle u-z, x_{n_{k}}-z\right\rangle=\left\langle u-z, x^{*}-z\right\rangle .
$$

It follows from (3.9), (3.10) and $\alpha_{n_{k}} \rightarrow 0$ that

$$
\lim _{k \rightarrow \infty} \frac{\rho_{n_{k}}}{\alpha_{n_{k}}}\left\|y_{n_{k}}\right\|^{2}
$$

exists. Therefore, we obtain from condition $(d)$ that

$$
\left\|y_{n_{k}}\right\|^{2}=\frac{\alpha_{n_{k}}}{\rho_{n_{k}}} \frac{\rho_{n_{k}}}{\alpha_{n_{k}}}\left\|y_{n_{k}}\right\|^{2} \rightarrow 0
$$

that is,

$$
\lim _{k \rightarrow \infty}\left\|y_{n_{k}}\right\|=\lim _{k \rightarrow \infty}\left\|x_{n_{k}}-S x_{n_{k}}+A^{*}(I-T) A x_{n_{k}}\right\|=0,
$$

which, together with Lemma 3.2, implies that

$$
\lim _{k \rightarrow \infty}\left\|x_{n_{k}}-S x_{n_{k}}\right\|=\lim _{k \rightarrow \infty}\left\|(I-T) A x_{n_{k}}\right\|=0 .
$$

Therefore by the condition $(a)$ we have $x^{*} \in F(S)$ and $A x^{*} \in F(T)$, i.e., $x^{*} \in \Omega$. So from (3.9), (3.10) and (2.2) we obtain

$$
\limsup _{n \rightarrow \infty} b_{n} \leq \lim _{k \rightarrow \infty}\left\langle u-z, x_{n_{k}}-z\right\rangle=\left\langle u-z, x^{*}-z\right\rangle \leq 0 .
$$

Finally, we show that $\left\{x_{n}\right\}$ converges strongly to $z=P_{\Omega} u$. The condition $(b)$ implies that $\sum_{n=0}^{\infty} \rho_{n}^{2} M<$ $\infty$. Applying Lemma 2.1 to (3.8) we get from condition $(c)$ that $\left\|x_{n}-z\right\| \rightarrow 0$, that is, the sequence $\left\{x_{n}\right\}$ converges strongly to $z=P_{\Omega} u$. This completes the proof.

Remark 3.1. Choose $\rho_{n}=2 \tau \frac{1}{(n+1)^{r}}, \alpha_{n}=\frac{1}{(n+1)^{s}}, \frac{1}{2}<r<s \leq 1$, where

$$
\tau=\frac{\min \{1-\beta, 1-\mu\}}{4 \max \left\{1,\|A\|^{2}\right\}} .
$$

These sequences $\left\{\rho_{n}\right\}$ and $\left\{\alpha_{n}\right\}$ satisfy conditions $(b)-(d)$ in Theorem 3.1.

If $S$ and $T$ are nonexpansive with $F(S) \neq \emptyset$ and $F(T) \neq \emptyset$, then $S$ and $T$ are demicontractive. By using Lemma 2.3, the condition (a) in Theorem 3.1 is satisfied. Using Theorem 3.1, we have the following corollary. 
Corollary 3.1. If $S$ and $T$ are two nonexpansive mappings and $\Omega \neq \emptyset$. The sequences $\left\{\alpha_{n}\right\}$, $\left\{\rho_{n}\right\}$ and the operator A satisfied the conditions in Theorem 3.1. Then the sequence $\left\{x_{n}\right\}$ generated by Algorithm 3.1 converges strongly to a solution $z$ of problem (1.1), where $z=P_{\Omega} u$.

\section{Acknowledgments}

The authors are grateful to the reviewers for useful suggestions which improved the contents of this paper. The second author was supported by Zhejiang Provincial Natural Science Foundation of China under Grants No. LQ13A010007 and LY14A010006.

\section{REFERENCES}

[1] Y. Censor, T. Elfving, A multiprojection algorithm using Bregman projections in a product space, Numer. Algorithms 8 (1994), 221-239.

[2] Y. Censor, A. Segal, The split common fixed point problem for directed operators, J. Convex Anal. 16 (2009), $587-600$.

[3] S.Y. Cho, et al., Viscosity approximation splitting methods for monotone and nonexpansive operators in Hilbert spaces, J. Nonlinear Convex Anal. 19 (2018), 251-264.

[4] K. Goebel, W.A. Kirk, Topics in Metric Fixed Point Theory, vol. 28 of Cambridge Studies in Advanced Mathematics, Cambridge University Press, Cambridge, 1990.

[5] A. Moudafi, The split common fixed-point problem for demicontractive mappings, Inverse Probl. 73 (1967), $591-597$.

[6] G. Marino, H.K. Xu, Weak and strong convergence theorems for strict pseudo-contractions in Hilbert spaces, J. Math. Anal. Appl. 329 (2007), 336-346.

[7] Z. Opial, Weak convergence of the sequence of successive approximations for nonexpansive mappings, Bull. Amer. Math. Soc. 73 (1967), 591-597.

[8] X. Qin, A. Petrusel, J.C. Yao, CQ iterative algorithms for fixed points of nonexpansive mappings and split feasibility problems in Hilbert spaces. J. Nonlinear Convex Anal. 19 (2018), 157-165.

[9] Y. Shehu, F.U. Ogbuisi, An iterative algorithm for approximating a solution of split common fixed point problem for demicontractive maps, Dyn. Contin. Discrete Impuls. Syst. Ser. B Appl. Algorithms 23 (2016), 205-216.

[10] W. Takahashi, Nonlinear Functional Analysis, Yokohama Publishers, Yokohama, 2000.

[11] F. Wang, A new method for split common fixed-point problem without priori knowledge of operator norms, J. Fixed Point Theory Appl. 19 (2017), 2427-2436

[12] Y. Wang, T.H. Kim, Simultaneous iterative algorithm for the split equality fixed-point problem of demicontractive mappings, J. Nonlinear Sci. Appl. 10 (2017), 154-165.

[13] Y. Wang, T.H. Kim, X. Fang, H. He, The split common fixed-point problem for demicontractive mappings and quasinonexpansive mappings, J. Nonlinear Sci. Appl. 10 (2017), 2976-2985.

[14] F. Wang, H.-K. Xu, Cyclic algorithms for split feasibility problems in Hilbert spaces, Nonlinear Anal. 74 (2011), $4105-$ 4111.

[15] Z. Xue, H. Zhou, Y.J. Cho, Iterative solutions of nonlinear equations for m-accretive operators in Banach spaces, J. Nonlinear Convex Anal. 1 (2000), 313-320.

[16] Y. Yao, M. Postolache, X. Qin, J.C. Yao, Iterative algorithms for the proximal split feasibility problem, U.P.B. Sci. Bull., Series A 10 (2018), 37-44.

[17] Y. Yao, Y.C. Liou, J.C. Yao, Split common fixed point problem for twoquasi-pseudo-contractive operators and its algorithm construction, Fixed Point Theory Appl. 2015 (2015), Art. ID 127.

[18] Y. Yao, J.C. Yao, Y.C. Liou, M. Postolache, Iterative algorithms for split common fixed points of demicontractive operators without priori knowledge of operator norms, Carpathian J. Math. 34 (2018), 451-458. 